\title{
The relationship between basal and luminal cytokeratins with histopathologic characteristics of canine mammary gland cancer
}

\author{
D. Eivani, P. Mortazavi \\ Department of Pathology, Faculty of Specialized Veterinary Sciences, Science and Research Branch, \\ Islamic Azad University, Tehran, Iran
}

\begin{abstract}
Neoplasia occurs mostly in mammary glands in female dogs and mammary gland cancer is one of the causes of death in these animals cytokeratins are one of the most important of tumor markers for identification of tumor prognosis.

In this study, 120 canine malignant tumor samples of mammary glands were studied. From each sample, a section was taken for hematoxylin-eosin staining and two sections for immunohistochemical staining of markers CK5/6 and CK7. Histopathology slides was evaluated by light microscope.

The results show that the presence of markers CK7 and CK5/6 had no significant relationship with tumor grade and type $(\mathrm{p}<0.05)$.

However, it seems that unlike humans, CK5/6 and CK7 is not an independent prognostic factor in canine mammary gland tumors.
\end{abstract}

Key words: canine mammary gland tumors, basal cytokeratin, luminal cytokeratin

\section{Introduction}

The prevalence of mammary neoplasms was reported 199 per 100,000 female dogs (Santini et al. 2002). Recent studies on gene expression have identified two major groups of breast cancer cells, one with basal/myoepithelial characteristics and the other with luminal characteristics (Gama et al. 2010). The important point is the prognosis of basal type cancers because they are associated with poor clinical outcome. Basal tumors are hormone receptor-negative and express genetic characteristics of basal and myoepithelial cells (Gama et al. 2010).

Intermediate filaments (IFs) are one of the most important types of tumor markers, whose presence or absence is very important (White and Hahn 2003). A large group of IFs is known as cytokeratins, which are specific for epithelial cells and carcinomas. Most malignant tumors are highly consistent, due to their strong cytoskeleton which is made of cytokeratin pro-

Correspondence to: P. Mortazavi, e-mail: sp.mortazavi@srbiau.ac.ir, tel.: +989 122309512 
teins. These proteins may be released into serum and other body fluids following the neoplastic transformation of these cells and the incidence of carcinoma (Gusterson et al. 2005). Certain structural proteins in cytoskeletal IFs may have a relative relationship with biological behavior and prognosis of breast cancer in humans. In fact, the immunological expression of basal cytokeratins such as CK17, CK14 and CK5 has been associated with poor prognosis ( $\mathrm{Gu}$ et al. 2008). Recently, prognostic value of several molecular variables has been examined in studies of canine mammary gland carcinoma (Gama et al. 2010). These variables include cell proliferation markers (Warapan et al. 2009, Gama et al. 2010), receptor proteins (Gama et al. 2010), oncogenes/tumor suppressor genes (Gama et al. 2008) and adhesion molecules (Gama et al. 2010), among others variables (Queiroga et al. 2005, Pinho et al. 2007). Despite the popularity of these variables as diagnostic indicators related to human breast cancer, some of them have expressed conflicting results and are still invalid in veterinary medicine. This study aimed to investigate the association of expression of basal and luminal cytokeratins 5/6 and 7 with prognosis and tumor malignity grade and compare it with histopathologic characteristics of canine mammary tumors.

\section{Materials and Methods}

All samples were collected from pet hospitals and polyclinics in Tehran, IRAN. The inclusion criteria were the following: primary malignant tumor, not being recurrent. Some samples were excluded for their inappropriate tissue fixation, and if samples were found benign after the pathology study, they were also excluded. Finally, 120 malignant tumor samples were selected. All information in the records of dogs were examined carefully, including age, previous history of mammary disease, the results of ultrasound and radiology, the position of the involved mammary glands, the tumor size at the time of excision, axillary and inguinal lymph nodes status, type of surgery and status of local invasion or metastasis.

\section{Preparation of samples}

After obtaining samples, they were fixed for 24 hours in $10 \%$ formalin buffer solution and paraffin blocks were prepared. Each block was used for a 6-fm thick section for hematoxylin-eosin staining and two $4-\mu \mathrm{m}$ thick sections for immunohistochemical staining. A 4- $\mu \mathrm{m}$ thick section was prepared without adding primary antibody as negative control. Normal human breast and skin tissues were used as positive control for CK7 and CK5/6.

\section{Immunohistochemical staining}

Samples confirmed as malignant were stained by IHC method with the following antibodies: Ab-CK5/6: (Dako, Denmark, code M7237, GA780, IR780, IS780) and Ab-CK7: (Dako, Denmark, code M7018, GA619, IR619, IS619). Immunohistochemical staining of samples was performed according to the antibodies manufacturer's instructions.

\section{Histological evaluation of mammary glands cancer}

In this study, mammary cancer grading was performed according to Table 1 and 2 (Goldschmidt et al. 2011).

Clinical cancer staging (TNM) was carried out according to the protocol recommended by Owen 1980 (Cassali et al. 2011) as shown in Table 3 and 4.

\section{Evaluation of CK5/6 and CK7 expression by IHC technique}

Immunoexpression of CK5/6 and CK7 in breast cancer tissue were investigated in 10 microscopic fields at a magnification of 400x. The percentage of immunoexpression was regardless of staining intensity and only staining rate was considered. It should be noted that the immune reaction is exclusively considered in membranes of invasive epithelial cells in the tumor stroma. The expression of each cytokeratins 5/6 and 7 was assessed as follows:

1. $0 \%$ (without immune response $)=$ null or negative

2. $1-10 \%:=+1$ or weakly positive

3. $150-50 \%=+2$ or moderately positive

4. $>50 \%=+3$ or strongly positive

Tumor grading and scoring for each parameter were performed according to proposed guidelines of Goldschmidt et al. (2011).

\section{Statistical analysis}

The correlations between CK7 and tumor grade and type and CK5/6 and tumor grade and type were assessed by Spearman test. The results were analyzed by statistical SPSS-18 software. The significance level was considered $\mathrm{p} \leq 0.05$. 
Table 1. Criteria for Histologic Malignant Grade.

\begin{tabular}{cccc}
\hline & Tubule Formation & Nuclear Pleomorphism & Mitoses per 10 High Power Field \\
\hline 1 point & $\begin{array}{c}\text { Tubule formation }>75 \% \\
\text { of the specimen }\end{array}$ & $\begin{array}{c}\text { Uniform or regular small nucleus } \\
\text { and occasional nucleoli }\end{array}$ & $0-9$ mitoses \\
\hline 2 point & $\begin{array}{c}\text { Moderate formation of tubular } \\
\text { arrangements }(10-75 \% \text { of the } \\
\text { specimen) admixed with areas } \\
\text { of solid tumor growth }\end{array}$ & $\begin{array}{c}\text { Moderate degree of variation } \\
\text { in nuclear size and shape, } \\
\text { hyperchromatic nucleus, } \\
\text { and presence of nucleoli } \\
\text { (some of which can be prominent })\end{array}$ & 10-19 mitoses \\
\hline point & Minimal or no tubule formation \\
& $(<10 \%)$ & $\begin{array}{c}\text { Marked variation in nuclear size } \\
\text { and hyperchromatic nucleus, } \\
\text { often with one or more prominent } \\
\text { nucleoli }\end{array}$ & $>20$ mitoses \\
& & &
\end{tabular}

Table 2. Histologic malignancy grade of canine mammary glands carcinoma.

\begin{tabular}{cc}
\hline Total Score & Grade of Malignancy \\
\hline $3-5$ point & I (low) \\
\hline $6-7$ point & II (intermediate) \\
\hline $8-9$ point & III (High) \\
\hline
\end{tabular}

Table 3. Clinical staging (TNM) of canine mammary carcinomas.

\section{Primary tumor $(\mathrm{T})$}

T0 No evidence of primary tumor

T1 Tumor size $<3 \mathrm{~cm}$ a: not attached

b: attached to the skin

c: attached to the muscle

T2 Tumor size $3-5 \mathrm{~cm}$ a: not attached

b: attached to the skin

c: attached to the muscle

T3 Tumor size $>5 \mathrm{~cm}$ a: not attached

b: attached to the skin

c: attached to the muscle

\section{Regional lymph nodes $(\mathrm{N})$}

N0 No regional lymph node metastasis (axillary or inguinal)

N1 Ipsilateral lymph node involved

a: not attached

b: attached

N2 Bilateral lymph node involved

a: not attached

b: attached

Distant metastasis (M)

M0No distant metastasis

M1 Distant metastasis, including distant lymph nodes

T4 Tumor of any size (Inflammatory carcinoma)

Table 4. Grouping by stages of canine mammary tumors.

\begin{tabular}{|c|c|c|c|}
\hline & $\mathbf{T}$ & $\mathbf{N}$ & $\mathbf{M}$ \\
\hline Stage I & $\mathrm{T} 1$ & $\mathrm{~N} 0 ; \mathrm{N} 1 \mathrm{a}$ or $\mathrm{N} 2 \mathrm{a}$ & M0 \\
\hline \multirow[t]{3}{*}{ Stage II } & $\mathrm{T} 0$ & $\mathrm{~N} 1$ & \\
\hline & $\mathrm{T} 1 \mathrm{a}, \mathrm{b}$ or $\mathrm{c}$ & N1 & \\
\hline & $\mathrm{T} 2 \mathrm{a}, \mathrm{b}$ or $\mathrm{c}$ & N0 or N1a & M0 \\
\hline \multirow[t]{2}{*}{ Stage III } & All T3 & All N & \\
\hline & All T & All Nb & M0 \\
\hline Stage IV & All T & All N & M1 \\
\hline
\end{tabular}

$\mathbf{T}$ - Size of primary tumor; $\mathbf{N}$ - Lymph node; $\mathbf{M}$ - Metastasis 
Results

\section{Histopathological type of tumor}

Among 120 samples surveyed, there were eight types of tumors as seen in Fig. 1.

\section{Tumor staging}

The results of tumor staging are shown in Fig. 2.

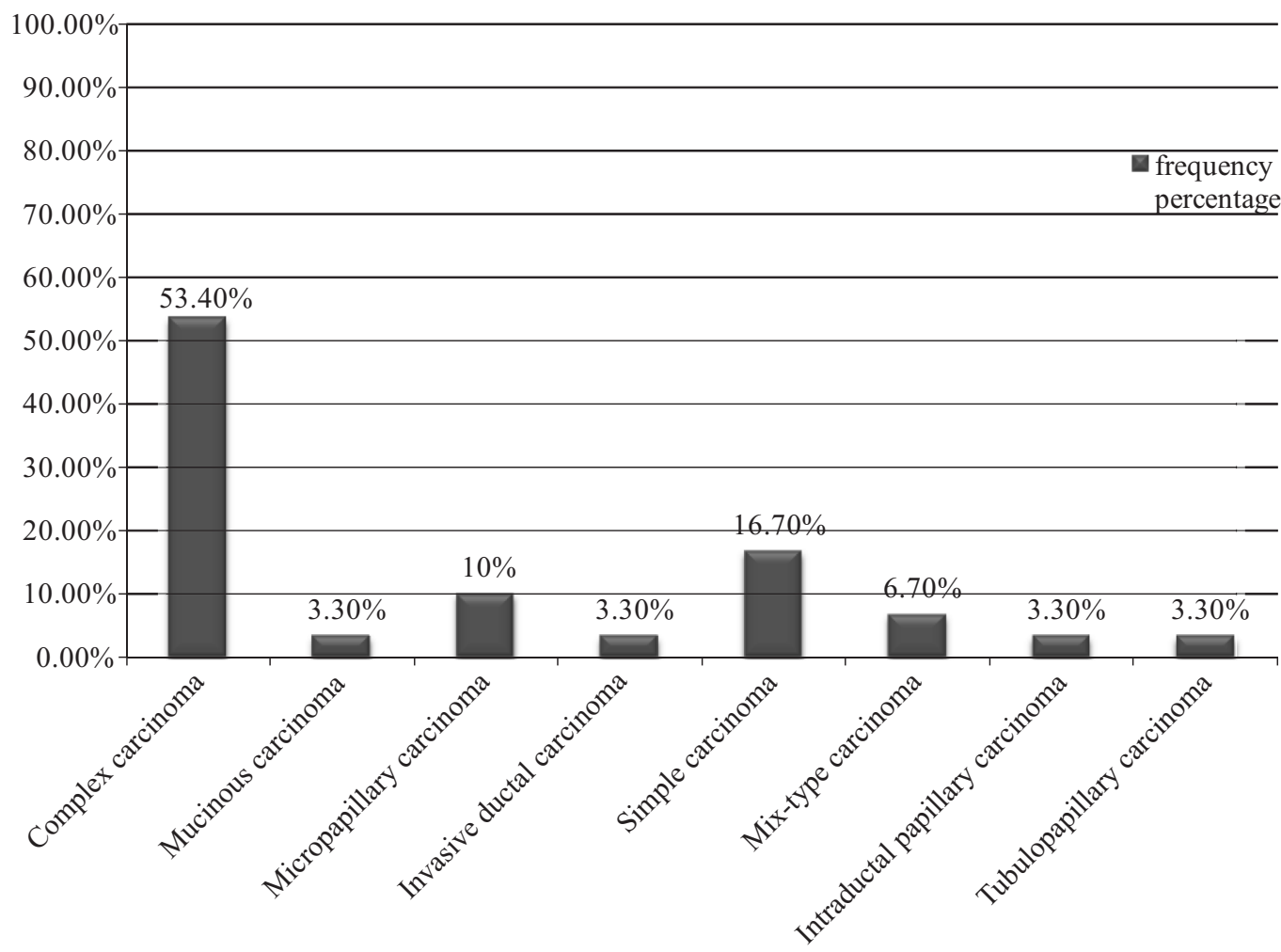

Fig. 1. Relative frequency of canine mammary gland cancer.

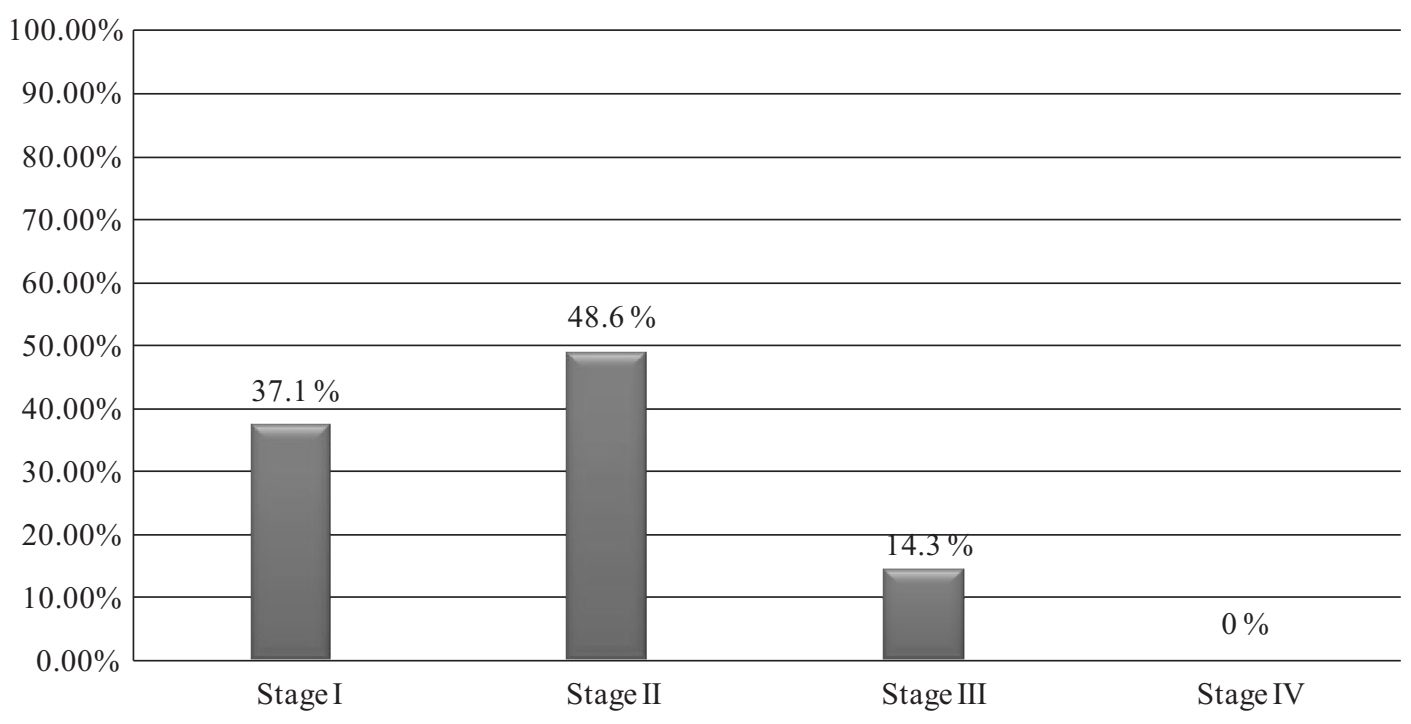

Fig. 2. Staging of canine mammary gland carcinoma according to T.N.M system. Stage II has the highest number of samples. 


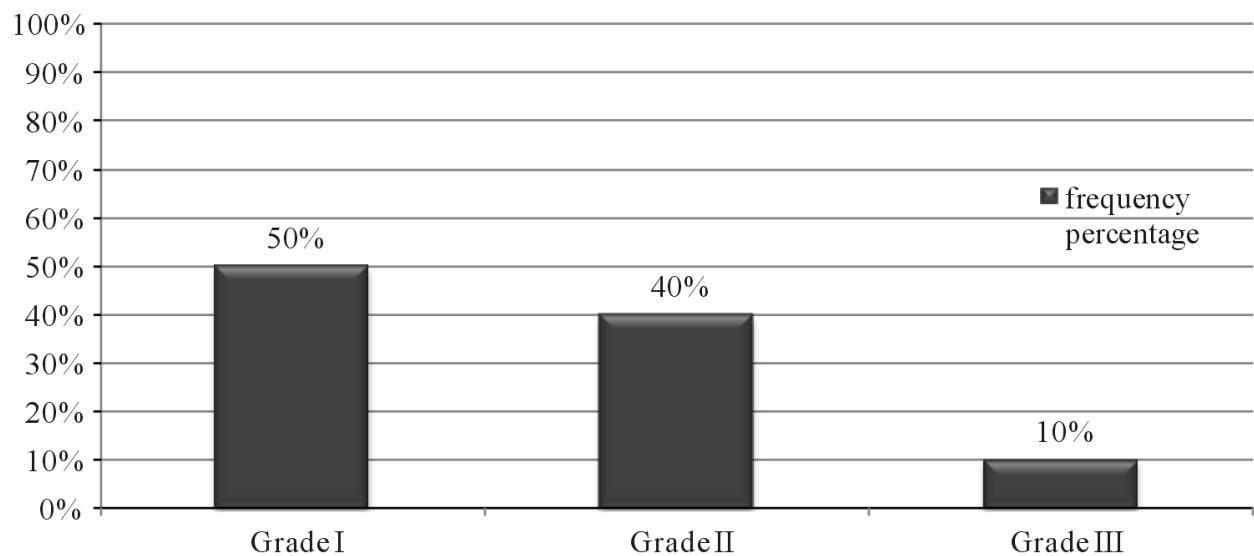

Fig. 3. Relative frequency of mammary gland carcinoma grade.

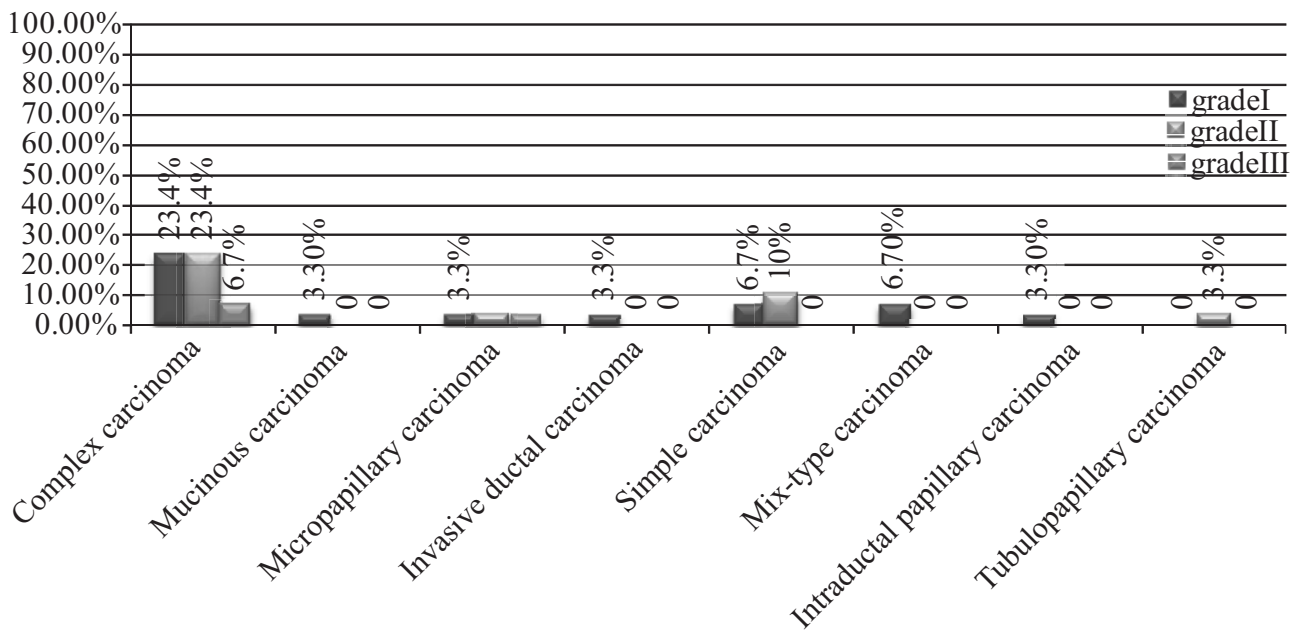

Fig. 4. Frequency of tumor grades by the type of tumor.

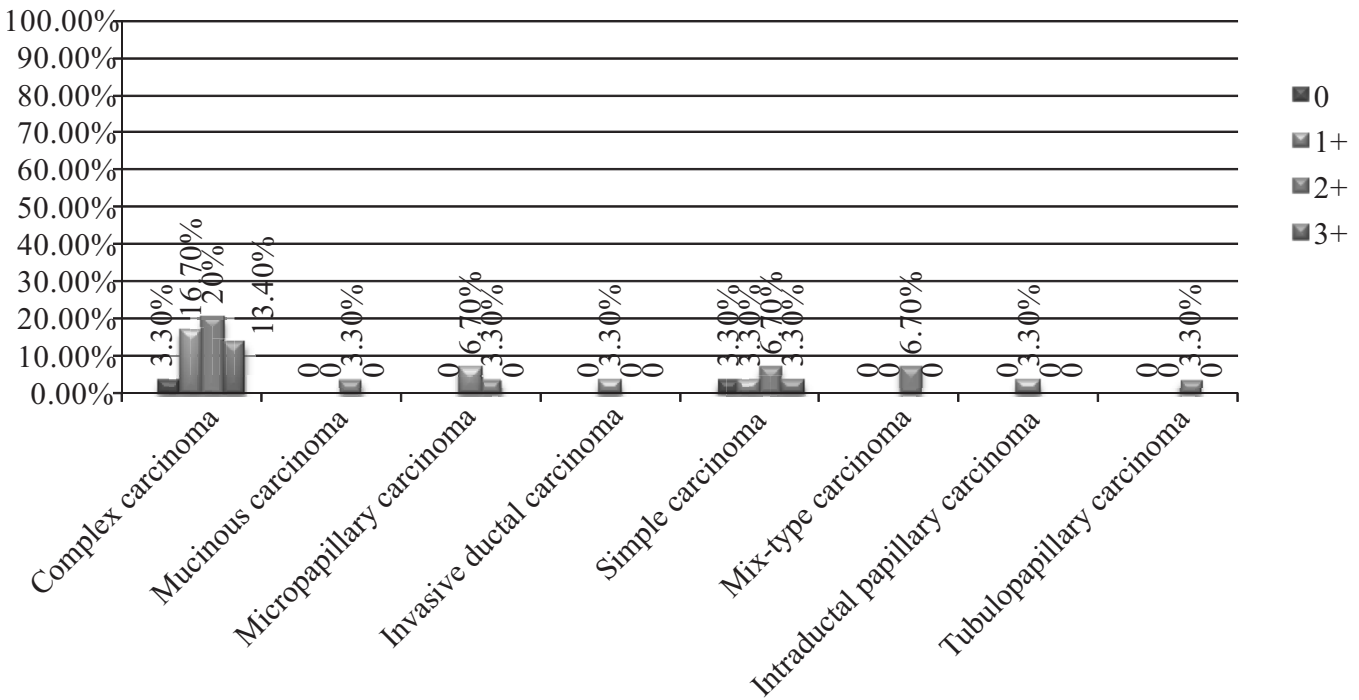

Fig. 5. Relative frequency of the severity of CK 5/6 expression according to tumor type. 


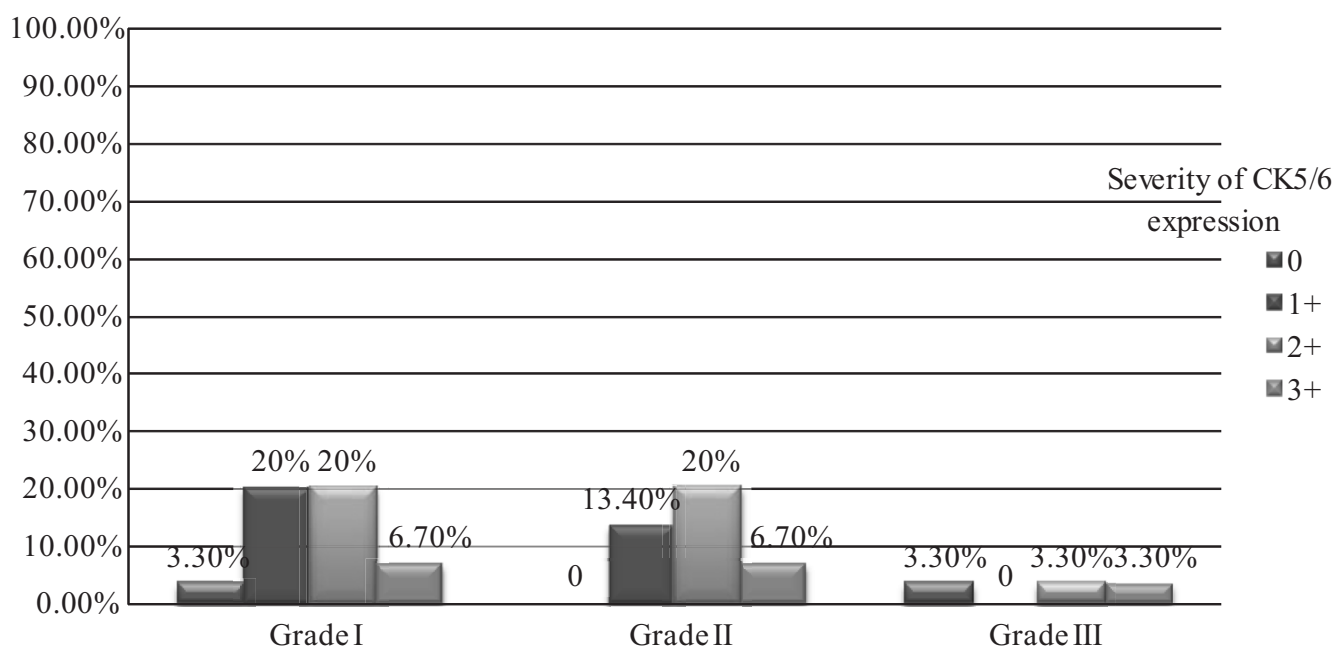

Fig. 6. Relative frequency of the serverity of CK 5/6 expression according to tumor grade.

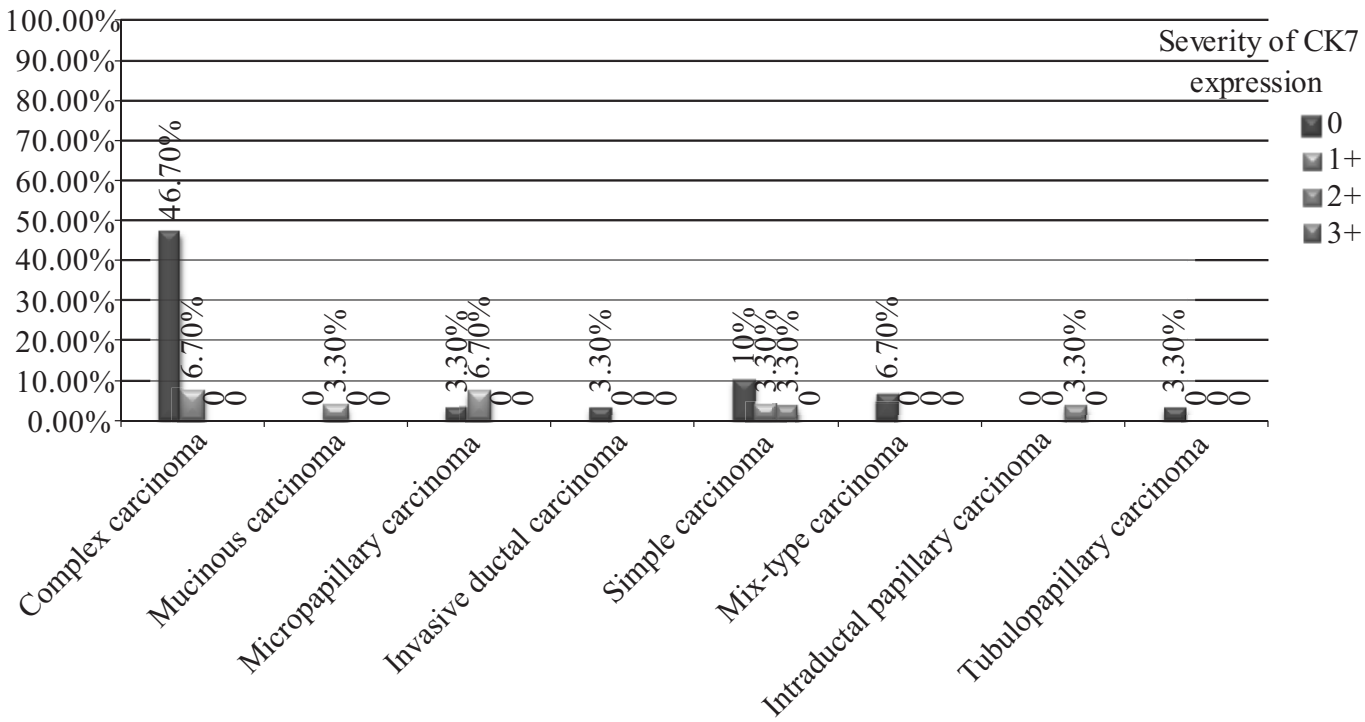

Fig. 7. Relative frequency of the serverity of CK 7 expression according to tumor type.

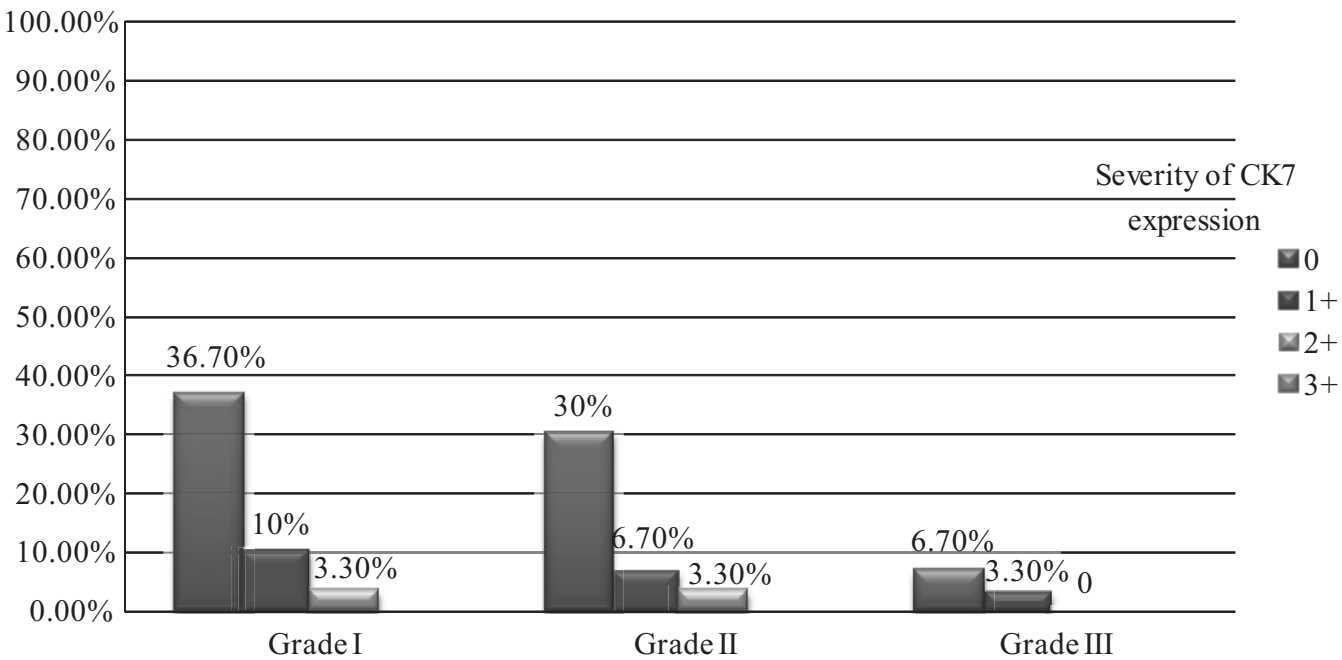

Fig. 8. Relative frequency of the serverity of CK 7 expression according to tumor grade. 

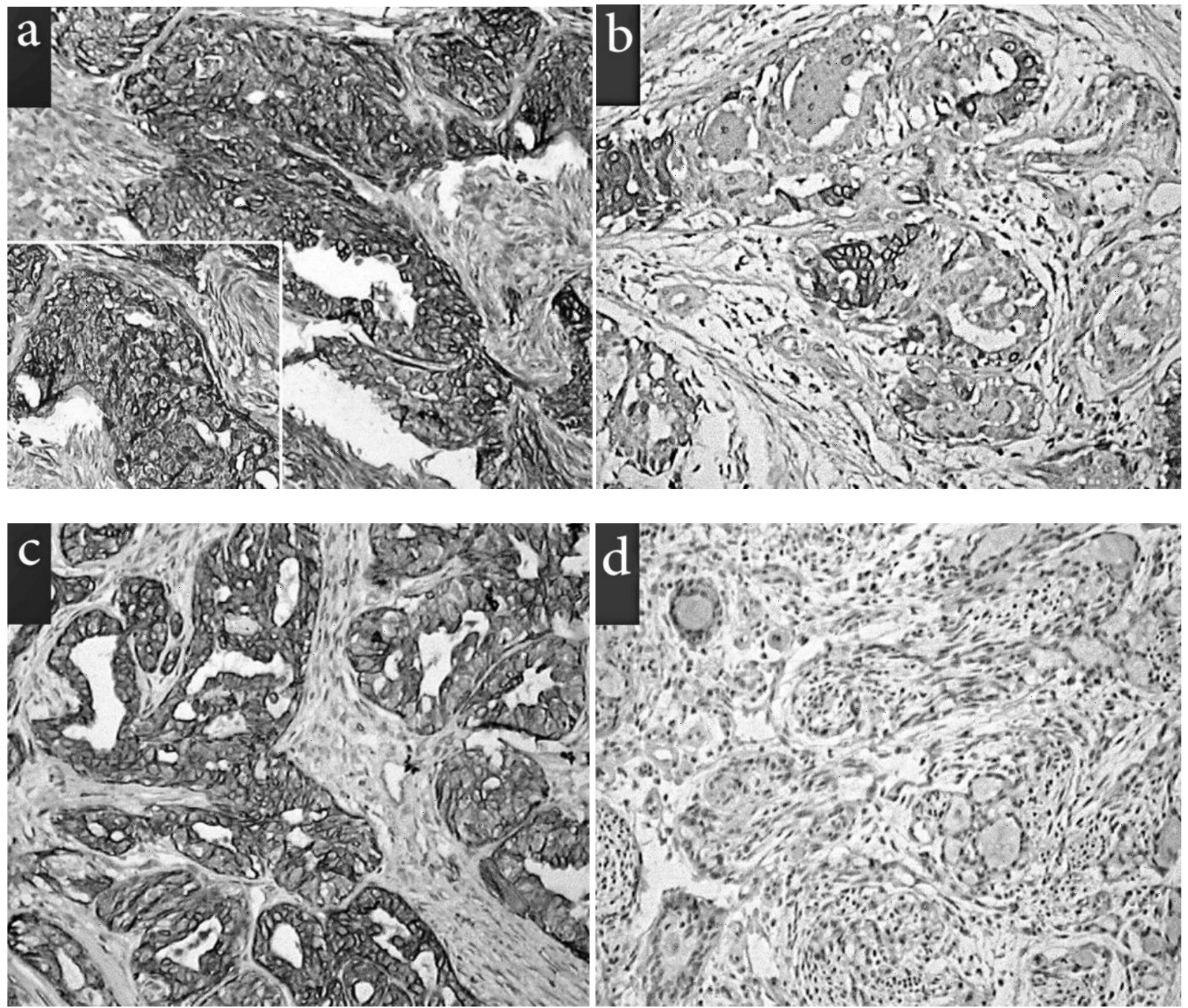

Fig. 9. Micrographs of canine mammary gland tumors - immunohistochemical staning: a - High expression of cytokeratin $5 / 6$ (magnification $\times 200$ ), the bottom-left image (magnification $\times 400)$, b - Low expression of cytokeratin 5/6 (magnification $\times 200)$, c - High expression of cytokeratin 5/6 (magnification $\times 400)$, d - No expression of cytokeratin $5 / 6($ magnification $\times 400)$

\section{Evaluation of CK5/6 with immunohistochemical staining}

In Figs. 5 and 6 the expression frequency of CK5/6 is presented according to tumor type and grade. Fig. 9 shows the micrographs of immunohistochemical staining for CK5/6.

\section{Evaluation of CK7 with immunohistochemical staining}

In Figs. 7 and 8 expression frequency of CK7 is shown according to tumor type and grade.

\section{Statistical analysis results}

The results of statistical analysis show that if the expression of $\mathrm{CK} 5 / 6$ and $\mathrm{CK} 7$ is considered zero, $1+$,
$2+$ and $3+$, the presence of these markers has no significant relationship with tumor grade and type $(\mathrm{p}<$ $0.05)$.

Ignoring the severity of expression and considering only the expression or lack of expression of CK5/6 and CK7, only CK5/6 is significantly associated with tumor type.

\section{Discussion}

Like in humans, identifying prognostic parameters is a major part of studies on canine mammary gland cancer. Although not completely, but several clinicopathological features are known as prognostic factors in most canine mammary gland cancer studies based on univariate or multivariate analysis: (1) tumor size (Muhammadnejad et al. 2012), (2) histological type of tumor (Andreia et al. 2013), (3) histological 
grade (Andreia et al. 2013), (4) the invasion rate (Gama et al. 2008) and (5) metastasis to lymph nodes and remote areas (Andreia et al. 2013). Karayannopoulou et al. (2005) used Elston and Ellis (1998) human grading method for histological grading of canine mammary gland tumors and reported it useful for predicting tumors. This method (based on tubule formation, nuclei pleomorphism and mitoses count) is apparently more reliable (Andreia et al. 2013). Factors that seem to have no effect on tumor prognosis include race, tumor site, the number of tumors and surgical method.

Nearly half of the canine mammary gland tumors are considered malignant and it is important to detect reliable prognostic factors for predicting the risk of an adverse clinical outcome (Birnbaum at al. 2004). The importance of cytokeratins expression is still unclear in prognosis estimation of canine mammary tumors (White and Hahn 2003, Warapan et al. 2009).

Some references report 10-11 years as the mean age for mammary gland neoplasia (White and Hahn 2003). In this study, most subjects were 8-10 years old and the mean age distribution was $8 \pm 0.4$ years. Given that carcinomas are the most common malignant tumors (White and Hahn 2003), all samples surveyed in this study related to mammary carcinoma.

Immunohistochemical studies show that the majority of luminal cells (CK7, CK8) and basal/myoepithelial cells (CK5, CK14) in normal human breast express p63 and P-Cadherin (Gama et al. 2004, Gama et al. 2008, Warapan et al. 2009). A significant relationship between basal phenotype and poor prognosis in human was reported in several studies and given that all of these cells can be affected by malignant changes, breast carcinomas are classified as expressing basal or luminal phenotypes (Abd El-Rehim et al. 2004, Gama et al. 2010).

Several reports have been published in human studies for luminal cytokeratin markers. These articles showed that the absence of luminal cytokeratins is significantly associated with tumor higher grade and more mitotic index (Abd El-Rehim et al. 2004, Willipinski-Stapelfeldt et al. 2005, Gama et al. 2010).

According to Moll et al. (1982) the biological significance of different expression of cytokeratin polypeptides is not clear in mammary carcinoma and although the performance of cytokeratins CK5, CK14, and CK17 is unknown, their expression is associated with poor prognosis. Moll's observations were confirmed by other researchers who found similar relationships between poor prognosis and expression of CK5, CK14, and CK17 (Gusterson et al. 2005).
In this research, we attempted to evaluate the immunohistochemical expression of luminal cell marker CK7 and basal cell marker CK5/6 in canine malignant mammary tumors and their possible association with a number of prognostic parameters. There was a significant difference in CK5/6 expression between grade I and II $(\mathrm{p}<0.05)$ and although we had an increase in CK5/6 expression in grade III tumors because there were few grade III tumors it was not comparable with the other two grades (I and II).

Based on the results, there was no significant difference in relation to CK7 in all tumor grades and it appears that CK7 cannot be an independent prognostic factor for malignant tumors in dogs, contrary to the findings in human. So the hypothesis of the relationship between the intensity of expression of luminal cytokeratin 7 and positive prognosis of tumor which has been considered in this study cannot be true.

Similar results were also obtained for basal cytokeratin 5/6. Statistical findings suggest that the presence of markers CK5/6 and CK7 does not show a significant relationship with tumor grade and type $(\mathrm{p}<0.05)$.

CK 5/6 can be considered an independent prognostic factor for malignant breast tumors in dogs provided that only the expression of CK5/6 and CK7 is considered, not the intensity of expression that can be attributed to the relationship between high tumor grade and positive basal markers according to the hypothesis of this study because according to previous findings, higher tumor malignancy causes higher expression of basal cytokeratins. However, because we considered the severity of expression in our study, no significant relationship was observed.

In Conclusion, it seems that unlike in humans, CK5/6 and CK7 are not independent prognostic factors in canine mammary gland carcinoma.

\section{Acknowledgments}

The authors would like to thank Dr. Ahad Mohammadnejad from Iran Cancer Institute, Tehran, for his help with sampling. Our appreciation goes to Dr. Etemad Mog-hadam's Lab especially to Dr. Gholamreza Etemad Moghadam and Ms. Maliheh Rezvan.

We would also like to thank Ms. Masoomeh Setareh from Cellular Molecular Lab, Gastrohepa-tology Research Center, Firoozgar Hospital, and also Dr. Reza Khansari and Dr. Reza Khandanlou from Faculty of Veterinary Sciences, Science and Research Branch, Islamic Azad University, Tehran. 


\section{References}

Abd El-Rehim DM, Pinder SE, Paish CE, Bell J, Blamey RW, Robertson JF, Nicholson RI, Ellis IO (2004) Expression of luminal and basal cytokeratins in human breast carcinoma. J Pathol 203: 661-671.

Birnbaum D, Bertucci F, Ginestier C, Tagett R, Jacquemier J, Charafe-Jauffret E (2004) Basal and luminal breast cancers: basic or luminous. Int J Oncol 25: 249-258.

Cassali GD, Lavalle GE, Ferreira E, Estrela-Lima A (2014) Consensus for the Diagnosis, Prognosis and Treatment of Canine Mammary Tumors. Braz J Vet Pathol, 7: 38-69.

Elston CW, Ellis IO (1998) Assessment of histological grade. In: Elston CW, Ellis IO (eds) Systemic Pathology - The Breast. Churchill and Livingstone, London, pp 365-384.

Gama A, Paredes J, Albergaria A, Gartner F, Schmitt $\mathrm{F}$ (2004) P-cadherin expression in canine mammary tissues. J Comp Pathol 130: 13-20.

Gama A, Alves A, Schmitt F (2008) Identification of molecular phenotypes in canine mammary carcinomas with clinical implications: application of the human classification. Virchows Archiv 453: 123-132.

Gama A, Alves A, Schmitt F (2010) Expression and prognostic significance of CK19 in canine malignant mammary tumours. Vet J 184: 45-51.

Goldschmidt MH, Pena L, Rasotto R, Zappulli V (2011) Classification and Grading of Canine Mammary Tumors. Vet Pathol 48: 117-131.

Gu X, Coates PJ, Boldrup L, Nylander K (2008) P63 contributes to cell invasion and migration in squamous cell carcinoma of the head and neck. Cancer Lett 263: 26-34.

Gusterson BA, Ross DT, Heath VJ, Stein T (2005) Basal cytokeratins and their relationship to the cellular origin and functional classification of breast cancer. Breast Cancer Res 7: 143-148

Karayannopoulou M, Kaldrymidou E, Constantinidis TC, Dessiris A (2005) Histological grading and prognosis in dogs with mammary carcinomas: application of a human grading method. J Comp Pathol 133: 246-252.

Moll R, Franke WW, Schiller DL, Geiger B, Krepler $\mathrm{R}(\mathbf{1 9 8 2})$ The catalog of human cytokeratins: patterns of expression in normal epithelia, tumors and cultured cells. Cell 31: 11-24.

Mohammadnejad A, Keyhani E, Mortazavi P, Behjati F, Haghdoost IS (2012) Overexpression of her-2/neu in Malignant Mammary Tumors; Translation of Clinicopathological Features from Dog to Human. Asian Pac J Cancer Prev 13: 6415-6421.

Pinho SS, Matos AJ, Lopes C, Marcos NT, Carvalheira J, Reis CA, Gartner F (2007) Sialyl Lewis X expression in canine malignant mammary tumours: correlation with clinicopathological features and E-Cadherin expression. BMC Cancer 7: 124.

Queiroga FL, Perez-Alenza MD, Silvan G, Peña L, Lopes C, Illera JC (2005) Cox-2 levels in canine mammary tumors, including inflammatory mammary carcinoma: clinicopathological features and prognostic significance. Anticancer Res 25: 4269-4275.

Ribeiro GM, Bertagnolli AC, Rocha RM, Cassali GD (2012) Morphological Aspects and Immunophenotypic Profiles of Mammary Carcinomas in Benign-Mixed Tumors of Female Dogs. Vet Med Intl DOI: $10.1155 / 2012 / 432763$.

Santini D, Ceccarelli C, Tardio ML, Taffurelli M, Marrano D (2002) Immunocytochemical expression of epidermal growth factor receptor in myoepithelial cells of the breast. Appl Immunohistochem Mol Morphol 10: 29-33.

Santos AA, Lopes CC, Ribeiro JR, Martins LR, Santos JC, Amorim IF, Gärtner F, Matos AJ (2013) Identification of prognostic factors in canine mammary malignant tumours: a multivariable survival study. BMC Vet Res 9: 1.

Toniti W, Buranasinsup S, Kongcharoen A, Charoonrut P, Puchadapirom P, Kasorndorkbua C (2009) Immunohistochemical Determination of Estrogen and Progesterone Receptors in Canine Mammary Tumors. Asian Pac J Cancer Prev 10: 907-911.

White RAS, Hahn KA (2003) Reporoductive oncology and Diagnosis of neoplasia. In: Slatter D (ed) Textbook of small animal surgery, Elsevier science, USA, pp 2313-2324, 2437-2444.

Willipinski-Stapelfeldt B, Riethdorf S, Assmann V, Woelfle U, Rau T, Sauter G, Heukeshoven J, Pantel K (2005) Changes in cytoskeletal protein composition indicative of an epithelial-mesenchymal transition in human micrometastatic and primary breast carcinoma cells. Clin Cancer Res 11: 8006-8014. 